\title{
A multi-stage linear prediction model for the irregularity of the longitudinal level over unit railway sections
}

\author{
H. Chang ${ }^{1}$, R. Liu ${ }^{1} \&$ Q. Li $^{2}$ \\ ${ }^{1}$ State Key Laboratory of Rail Traffic Control and Safety, \\ Beijing Jiaotong University, China \\ ${ }^{2}$ School of Traffic and Transportation, Beijing Jiaotong University, China
}

\begin{abstract}
Various researchers, both at home and abroad, have developed models to predict the irregularity of longitudinal level changes, which take into account different influential factors. In order to help the railway maintenance department to more accurately grasp the pattern of irregularity of longitudinal level changes, the present authors have developed a new model that uses historical track geometry inspection data from track inspection cars to predict the irregularity of longitudinal level changes for unit railway sections (which are taken as 200 metres long in this paper). Various factors affect the irregularity of the track. These mainly include train operation factors, track structure and environmental factors. However, for a certain unit railway section, key consideration may be given to the impact of passing tonnage on the irregularity of the longitudinal level. This paper establishes linear regression equations that are only applicable to each particular unit section to fit the functional relationship between the irregularity of the longitudinal level and passing tonnage. The linear fit equations are obtained from standard deviations of inspected track level data at 200 intervals. The change curve of the irregularity of the longitudinal level is divided into several stages and these different stages are fitted with different linear regression equations. A multi-stage broken line is thus formed to approximate the pattern of changes in the irregularity of the longitudinal level. On this basis, the authors put forward a multi-stage linear prediction model for the irregularity of the longitudinal level. Finally, we use inspected data collected from the Beijing-Jiulong Railway Line in 2008 and 2009 to make predictions and validate the model.
\end{abstract}


Keywords: track, irregularity of longitudinal level, linear prediction model.

\section{Introduction}

Irregularity of the longitudinal level is a measure of railway track irregularity along the longitudinal direction [1]. With the fast construction of high-speed railways, the dynamic irregularity of longitudinal level research has attracted wide attention from researchers. When high-speed trains run on a railway line with a longitudinal level irregularity hazard, increased impact power will speed up ballast bed deformation, which in turn accentuates track irregularity and intensifies locomotive destruction to the railway track, thus forming a vicious cycle [2]. Research on the pattern of track longitudinal level irregularity changes can therefore help the railway maintenance department to formulate relevant line maintenance plans.

Iyengar and Jaiswal [3] have adopted the random process theory to analyze inspected track data from two railway lines in India and concluded that irregularity of the longitudinal level may be modelled as a stationary Gaussian random process. Alfelor et al. [4] have fitted linear equations to the loaded and unloaded gauge data measured by the Gauge Restraint Measurement System (GRMS) and used these equations to describe the relationship between the gauge and each of the several factors affecting it. Hyslip [5] has conducted fractal analysis of track geometry data and developed numerical indices for assessing track condition. Kawaguchi et al. [6] at the Railway Technical Research Institute in Japan have respectively developed degradation models that use standard deviations of track irregularities to predict the standard deviations of both track alignment and surface over 100m track sections. Chen [7] at the China Academy of Railway Sciences has developed an integrated factor method that uses TGCgenerated track waveform data to predict track irregularities at a single mileage point. Railway experts in Canada have developed a linear prediction model with TQI as the index. Xu $[1,8]$ in China has developed a linear fitting model to predict TQI and a characteristic matrix method-based model to predict the irregularity of longitudinal level. To make more accurate predictions for the irregularity of longitudinal level changes on railway lines in China, the present authors conduct their research on the following two aspects:

(1) Changes in the irregularity of the track are related to track condition, operational conditions and various other factors. Based on the prediction models in $\mathrm{Xu}[1,8]$, this paper puts forward a new prediction model for the irregularity of the longitudinal level. Between two adjacent maintenances, irregularity of the longitudinal level is mainly affected by train operation conditions, railway track structure and environmental changes. However, for a specific unit section where other factors are relatively fixed, passing tonnage exerts the most significant influence on the irregularity of longitudinal level. We therefore focus our research on such an impact so as to unravel the relationship between passing tonnage and local irregularity of the longitudinal level and predict track longitudinal level changes on unit railway sections. 
(2) Between two adjacent maintenances, the irregularity of the longitudinal level on a specific unit railway section shows a pattern of multi-stage changes. In other words, as passing tonnage increases, the irregularity of the longitudinal level deterioration rate varies from one period to another within a cycle [9]. Based on the management values as specified in China's Railway Line Maintenance Regulations [10], we divide the irregularity of the longitudinal level deterioration process into different stages and establish a multi-stage prediction model.

\section{Model building}

\subsection{Characteristics of track longitudinal level irregularity changes}

Minor changes in track irregularity directly affect the operational safety of highspeed railways. Track irregularity is measured by eight indicators, namely gauge, and surface, left alignment, right alignment, left level, right level, twist and TQI (Track Quality Index). Track irregularity changes have been shown to exhibit three major characteristics [9]: periodicity, multi-stage and exponentiality. Periodicity means that the irregularity of longitudinal level change patterns over the same unit track section are similar between two adjacent track maintenances. Fig. 1 shows the change trend diagram of the TQI between two adjacent maintenances observed on the Beijing-Jiulong Railway Line at $\mathrm{K} 473+000 \sim \mathrm{K} 473+200$ during a spell of two years. Given such periodic changes, the authors define the period between two track maintenances as the time period for studying changes in track longitudinal level irregularity.

Multi-stage and exponential changes refer to that within one change cycle track irregularity deterioration rate varies from beginning to end and goes faster as passing tonnage increases (see Fig. 2). On Fig. 2, $\sigma_{T L D}$, i.e. the Y-axis is the standard deviation of the inspection data of track longitudinal level irregularity. Given such multi-stage and exponential changes, we divide one irregularity of

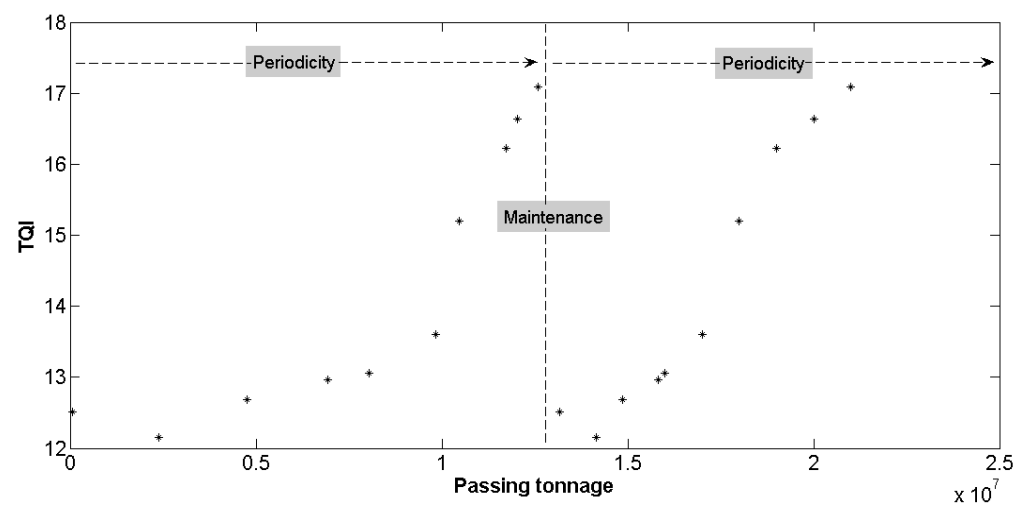

Figure 1: Schematic diagram of periodic changes of TQI on the BeijingJiulong railway line at K473+000 K473+200. 
longitudinal level change cycle into several stages and then use different linear equations to fit each stage. This way, a broken line of track longitudinal level irregularity changes is obtained and a Multi-stage Linear Prediction Model (MLPM) is established is to predict the irregularity of longitudinal level changes over a unit railway section.

\subsection{Data sources}

GJ-4 Track Geometry Car (TGC) is the most commonly used track inspection car in China. It is a strap down measuring system and adopts contactless and gyroscopic measurement technologies. Through its built-in software, GJ-4 TGC can sample and process track geometry data real time, performs automatic data modification, filtering and geometrical parameter synthesis, and display waveform data on a computer screen. Table 1 shows GJ-4 TGC's inspection items and their measurement accuracy.

GJ-4 TGC generates waveform data, off-limit data and TQI data. Among them, the TQI data, which include track longitudinal level data (i.e. TLD data), consists of the following fields: line name, direction, kilometre, metre, length, inspection speed, line form, eight geometric parameters and date of inspection. The maintenance department uses these data to formulate a maintenance operation plan [11]. In this paper, GJ-4 TGC-generated TLD and passing tonnage data from the Beijing-Jiulong Railway Line at K373+000 K649+000 in 2008 and 2009 were adopted. This railway line section is under the administration of the Jinan Railway Bureau.

$\sigma_{T L D}$ is calculated using eqn. (1):

$$
\sigma_{T L D}=\sqrt{\frac{1}{n} \sum_{i=1}^{n}\left(x_{i}^{2}-\bar{x}_{i}^{2}\right)}
$$

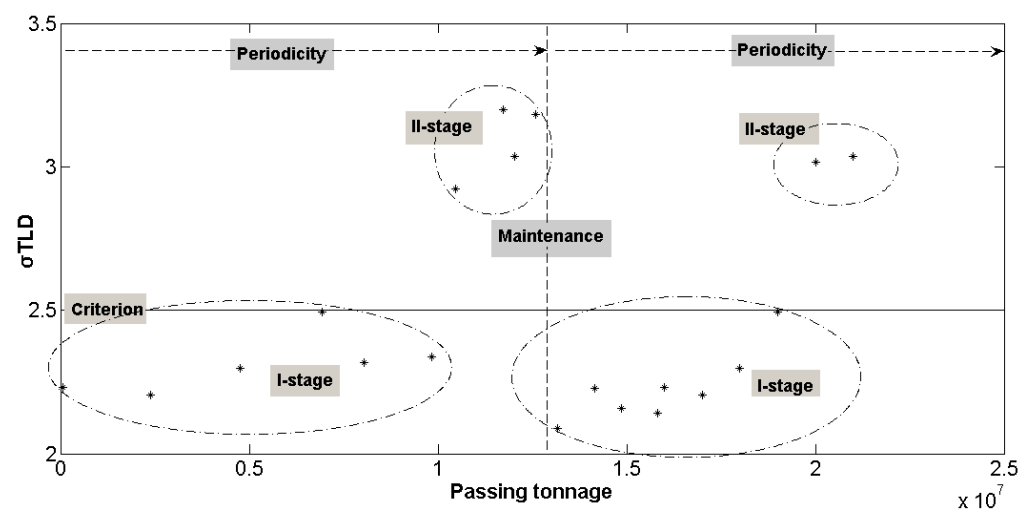

Figure 2: Multi-stage and exponential changes of track longitudinal level irregularity on the Beijing-Jiulong railway line at $\mathrm{K} 541+400 \sim \mathrm{K} 541+600$ (one track longitudinal level irregularity change cycle is divided into two stages: Stage I and Stage II). 
Table 1: Track geometrical parameters measured by GJ-4 and their accuracy.

\begin{tabular}{|c|c|c|}
\hline Item & Measuring Range & Accuracy \\
\hline Distance & $0 \sim 2999.9 \mathrm{Km}$ & $\leq \pm 1 \%$ o \\
\hline Speed & $0 \sim 160 \mathrm{Km} / \mathrm{h}$ & $\leq \pm 0.2 \mathrm{Km} / \mathrm{h}$ \\
\hline Gauge & $1415 \sim 1480 \mathrm{~mm}$ & $\leq \pm 0.8 \mathrm{~mm}$ \\
\hline Curvature & $\pm 230 / 30 \mathrm{~m}$ & $\leq \pm 1.0 \mathrm{~mm}$ \\
\hline Level and off-limit & $\pm 200 \mathrm{~mm}$ & $\leq \pm 1.0 \mathrm{~mm}$ \\
\hline Surface & $\pm 60 \mathrm{~mm}$ & $\leq \pm 1.5 \mathrm{~mm}$ \\
\hline Alignment & $\pm 100 \mathrm{~mm}$ & $\leq \pm 1.0 \mathrm{~mm}$ \\
\hline Twist & $\pm 100 \mathrm{~mm}$ & $\mathrm{~m} / \mathrm{s}^{2}$ \\
\hline $\begin{array}{c}\text { Train body's } \\
\text { vibration } \\
\text { acceleration }\end{array}$ & $\pm 9.8 \mathrm{~m} / \mathrm{s}^{2}$ & $\pm 9.8 \mathrm{~m} / \mathrm{s}^{2}$ \\
\hline $\begin{array}{c}\text { Axle box's vibration } \\
\text { acceleration }\end{array}$ & $\pm 980 \mathrm{~m} / \mathrm{s}^{2}$ & \\
\hline $\begin{array}{l}\text { Note: In China, a chord length of } 20 \mathrm{~m} \text { is adopted for surface and alignment } \\
\text { measurements. }\end{array}$ & \\
\hline \multicolumn{2}{|c|}{} \\
\hline
\end{tabular}

Table 2: $\quad$ Various management values for trunk lines at $<160 \mathrm{Km} / \mathrm{h}$.

\begin{tabular}{|c|c|c|c|c|c|c|}
\hline Item & Gauge & Level & Twist & Surface & $\begin{array}{c}\text { Longitudinal } \\
\text { Level }\end{array}$ & TQI \\
\hline Value & 1.6 & 1.9 & 2.1 & $2.2 * 2$ & $2.5 * 2$ & 15.0 \\
\hline
\end{tabular}

wherein: $x_{i}$ is the randomly sampled level value of Sampling Point $i$ on the unit track section;

$\bar{x}_{i}$ is the arithmetic mean of $x_{i}$ and

$n$ is the sample size. 4 points are sampled every metre and the total sample size for $200 \mathrm{~m}$ is: $\mathrm{n}=4 * 200=800$.

\subsection{Establishment of model}

Division of $\sigma_{T L D}$ changes into different stages: It is specified in [11] that for trunk railway lines with a running speed of $<160 \mathrm{~km} / \mathrm{h}$, a TQI value of $<15.0$ would be considered as indicating a balanced quality state, while a TQI value of $>15.0$ as suggesting the need to include the concerned lines into the maintenance plan. For such lines, the $\sigma_{T L D}$ management value is set to 2.5 (see Table 2) [11]. Four dynamic management levels are divided (see Table 3) [10]. These four levels are respectively Level I, the maintenance level; Level II, the train comfort level, Level III, the temporary repair level; and Level IV, the speed capping level. Based on Table 3, $\sigma_{\mathrm{TLD}}$ is divided into three stages, as shown in Table 4. 
Table 3: Dynamic track management value levels.

\begin{tabular}{|c|c|c|c|c|}
\hline Item & Level I & Level II & Level III & Level IV \\
\hline $\begin{array}{c}\text { Track longitudinal } \\
\text { level irregularity (mm) }\end{array}$ & 6 & 10 & 15 & 20 \\
\hline
\end{tabular}

Table 4: $\quad$ Division of $\sigma_{\mathrm{TLD}}$ stages.

\begin{tabular}{|c|c|c|c|}
\hline Item & Stage 1 & Stage 2 & Stage 3 \\
\hline$\sigma_{\mathrm{TLD}}$ & $0 \sim 2.5$ & $2.5 \sim 3.0$ & $>3.0$ \\
\hline
\end{tabular}

Multi-stage linear fit of $\sigma_{\mathrm{TLD}}$ : With reference to the different stages in Table 4, different linear equations are fitted to $\sigma_{\mathrm{TLD}}$ changes in each stage by the least square method. Let $\sigma_{(n)}$, i.e. $\sigma_{T L D}=\left\{\sigma_{(n)} \mid n=1,2,3 \ldots\right\}$, be the series of the TGCgenerated irregularity of longitudinal level data of the chosen unit track section. Corresponding to the three stages in Table $4, \sigma_{(n)}$ is split into three stages, as expressed in eqn. (2):

$$
\sigma_{(n)}=\left\{\sigma_{\mathrm{T} 0 \mathrm{i}}, \sigma_{\mathrm{T} \mathrm{j} j}, \sigma_{\mathrm{T} 2 \mathrm{k}}\right\}
$$

where $i=1,2,3, \ldots, j=1,2,3, \ldots, k=1,2,3, \ldots, \sigma_{\mathrm{T} 0 \mathrm{i}}$ is the inspection data of Stage 1. $\sigma_{\mathrm{T} 1 \mathrm{j}}$ is the inspection data of Stage 2 and $\sigma_{\mathrm{T} 2 \mathrm{k}}$ is the inspection data of Stage 3.

For each stage, $\sigma_{T L D}$ is calculated using eqn. (3):

$$
\sigma_{T n}=a_{n}+b_{n} * T_{n}
$$

where $n=1,2,3 \ldots b_{n}$ is the slope of Line $n, a_{n}$ is the intercept of Line $n$, and $\mathrm{T}_{n}$ is the total passing tonnage from last maintenance to the present day. Both $b_{n}$ and $a_{n}$ are calculated by the least square method.

Using eqn. (2) and eqn. (3), an MLPM is established. We use the track inspection data of 2008 and 2009 from the Jinan Railway Bureau to validate the model.

\section{Model validation}

We have developed a computer program for the MLPM, and use it to process the inspection data from the K373+000 K649+000 section which totally 184 kilometres on the Beijing-Jiulong Railway Line.

For the K373+000 K649+000 sections, 10 predictions are made, with stage, starting date, predicted date and number of days from the predicted date as the input parameters. For the predictions, the average absolute error is 0.09 , and the average relative error is $6.44 \%$. Figs. 3-6 show the typically predicted results for September 9, 2009. The waveforms compare the inspected data (grey waveform) with the predicted data (black waveform), with the $\mathrm{X}$-axis as mileage and the Yaxis the $\sigma_{\text {TLD }}$ value.

Due to limited space, we only use the K496+000 K496+200 unit section as an example to validate the model. 


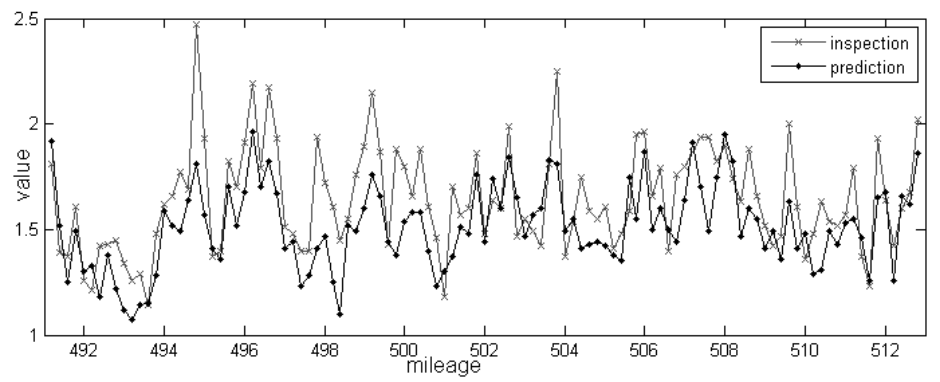

Figure 3: $\quad$ The September 9, 2009 waveform for the K491+200 K512+800.

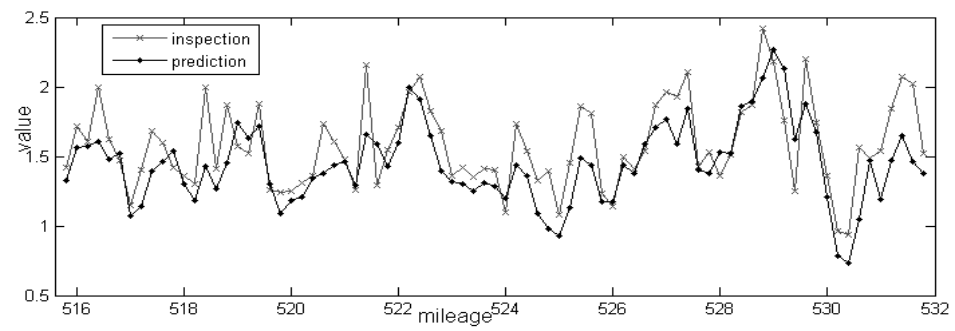

Figure 4: $\quad$ The September 9, 2009 waveform for the K515+800 K530+800.

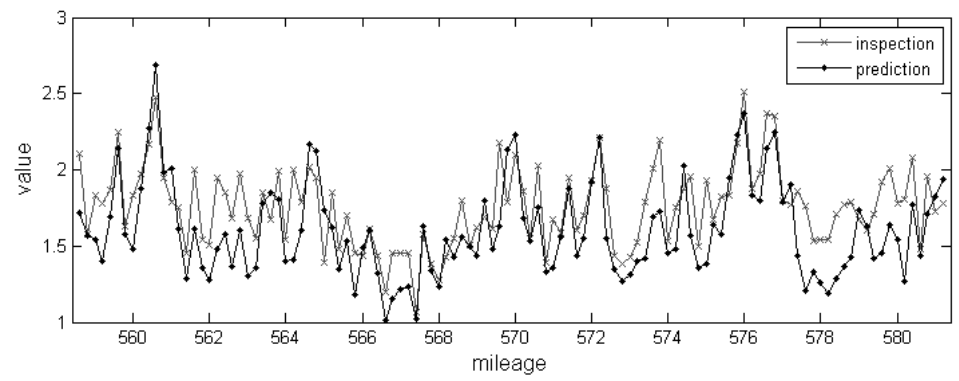

Figure 5: $\quad$ The September 9, 2009 waveform for the K558+600 K581+200.

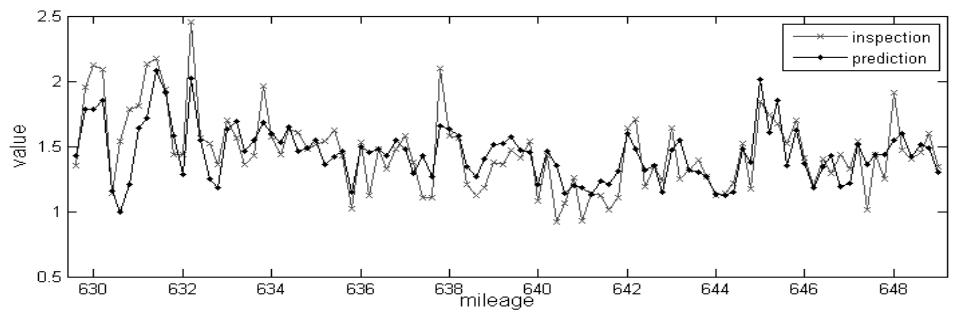

Figure 6: The September 9, 2009 waveform for the K629+600 K649+000. 


\subsection{Model validation with the K496+000 to K496+200 unit section}

This selected section runs from K496+000 to K496+200, with a total length of $200 \mathrm{~m}$. Table 5 lists some of the passing tonnage data, while Table 6 shows the inspected data of TLD collected in 2008 and 2009.

The inspected data of this section before 2008 are between 0 and 3.0. According to Table 4, Stages I and II are chosen to make linear fits and establish the MLPM for this section, which is shown in eqn. (4).

$$
\sigma_{T}^{\prime}=\left\{\begin{array}{l}
2 \times 10^{-8} \times T_{0 n}+2.220,\left(74558.4 \leq T_{0 n}<10471981\right) \\
1 \times 10^{-7} \times T_{1 n}+1.875,\left(10471981 \leq T_{1 n}<12584155\right)
\end{array}\right.
$$

wherein: $T_{0 n}$ and $T_{1 n}$ are respectively the accumulative passing tonnage from the inspection date of January 92008 in Stage 1 and 2. The linear fitting coefficient $\mathrm{R}^{2}$ is 0.389 for Stage 1 and 0.53 for Stage 2, while the multiple correlation coefficients $\mathrm{R}$ are 0.6236 and 0.7280 , respectively.

\subsection{Results analysis}

Eqn. (4) is used to predict for the data in Table 6. The predicted results and data analysis are shown in Table 7.

Table 5: $\quad$ Passing tonnages through the K496+000 K496+200 section.

\begin{tabular}{|c|c||c|c|}
\hline $\begin{array}{c}\text { Date of } \\
\text { Inspection }\end{array}$ & $\begin{array}{c}\text { Passing } \\
\text { Tonnage } \\
\text { (ton) }\end{array}$ & $\begin{array}{c}\text { Date of } \\
\text { Inspection }\end{array}$ & $\begin{array}{c}\text { Passing } \\
\text { Tonnage } \\
\text { (ton) }\end{array}$ \\
\hline 20080109 & 74558.4 & 20080625 & 9826317 \\
\hline 20080305 & 2378465 & 20080709 & 10471981 \\
\hline 20080407 & 4763551.2 & 20080808 & 11741065 \\
\hline 20080507 & 6941135.2 & 20080820 & 12027468 \\
\hline 20080521 & 8051939.8 & 20080909 & 12584155 \\
\hline
\end{tabular}

Table 6: $\quad$ Inspected data from the K496+000 K496+200 section.

\begin{tabular}{|c|c||c|c|}
\hline $\begin{array}{c}\text { Date } \\
\text { of Inspection }\end{array}$ & $\sigma_{\mathrm{TLD}}$ & $\begin{array}{c}\text { Date } \\
\text { of Inspection }\end{array}$ & $\sigma_{\mathrm{TLD}}$ \\
\hline 20080109 & 2.231 & 20080625 & 2.336 \\
\hline 20080305 & 2.206 & 20080709 & 2.924 \\
\hline 20080407 & 2.299 & 20080808 & 3.001 \\
\hline 20080507 & 2.495 & 20080820 & 2.935 \\
\hline 20080521 & 2.316 & 20080909 & 3.182 \\
\hline
\end{tabular}


Table 7: $\quad$ Absolute and relative errors of predicted $\sigma_{\mathrm{TLD}}$

\begin{tabular}{|c|c|c|c|}
\hline $\begin{array}{c}\text { Date } \\
\text { of Inspection }\end{array}$ & $\begin{array}{c}\text { Predicted } \\
\sigma_{\text {TLD }}\end{array}$ & $\begin{array}{c}\text { Absolute } \\
\text { Error }\end{array}$ & $\begin{array}{c}\text { Relative Error } \\
(\%)\end{array}$ \\
\hline 20080109 & 2.221 & 0.01 & 0.45 \\
\hline 20080305 & 2.268 & 0.062 & 2.81 \\
\hline 20080407 & 2.315 & 0.016 & 0.70 \\
\hline 20080507 & 2.358 & 0.137 & 5.49 \\
\hline 20080521 & 2.381 & 0.065 & 2.81 \\
\hline 20080625 & 2.417 & 0.081 & 3.47 \\
\hline 20080709 & 2.922 & 0.002 & 0.07 \\
\hline 20080808 & 3.049 & 0.048 & 1.60 \\
\hline 20080820 & 3.077 & 0.142 & 4.84 \\
\hline 20080909 & 3.133 & 0.049 & 1.54 \\
\hline
\end{tabular}

The absolute error is between 0.002 and 0.142 , while the minimum relative error is $0.07 \%$ and the maximum is $5.49 \%$. The predicted results thus well approximate to the inspected data.

\section{Conclusions}

(1) Massive TLD data and passing tonnage data from the Beijing-Jiulong Railway Line are analyzed in this paper. It is contended that total passing tonnage should be considered as the main influential factor when predictions are made irregularity of longitudinal level changes over a specific unit track section. Given that irregularity of longitudinal level possess multi-stage linear changes, the authors have developed a multi-stage linear prediction model to make predictions and provide technical support to the railway maintenance department.

(2) With reference to [10] and [11], the authors have divided into 3 stages track longitudinal level irregularity changes over the K373+000 K649+000 section of the Beijing-Jiulong Railway Line .

(3) Model validation with inspected data show that the MLPM which we have developed can make fairly accurate predictions for track longitudinal level irregularity, with an absolute error between 0.002 and 0.142 for a chosen section in the Beijing-Jiulong Railway Line.

\section{Acknowledgements}

The current research would not have been possible without the comprehensive technical support from the Railway Engineering Institute of the Jinan Railway Bureau. The authors deeply acknowledge and appreciate their continuous support. Meanwhile, this research project is sponsored by the National Key 
Technology Research and Development Program in China, under Project Number 2009BAG12A10.

\section{References}

[1] Xu, Y., Forecast Methods of Track Longitudinal Level Irregularity. Journal of Tonji University (Natural Science), 31(3), pp. 291 -295, 2003.

[2] General editorial committee of China railway encyclopaedia, China Railway Encyclopaedia - Volume on Engineering \& Railway Maintenance, China Railway Publishing House, pp. 153-154, 2004.

[3] Iyengar, R.N. \& Jaiswal, O.R., Random Field Modelling of Railway Track Irregularities. Journal of Transportation Engineering, 121(4), pp. 304-308, 1995.

[4] Alfelor, R.M., Carr, G.A. \& Fateh, M., Track Degradation Assessment Using Gage Restraint Measurements. Transportation Research Record, (1742), pp. 68-77, 2001.

[5] Hyslip, J.P., Fractal Analysis of Geometry Data. Transportation Research Record, (1785), pp. 50 - 57, 2002.

[6] Kawaguchi, A., Miwa, M. \& Terada, K., Actual Data Analysis of Alignment Irregularity Growth and its Prediction Model. Quarterly Report of RTRI, 46 (4), pp. 262 - 268, 2005.

[7] Chen, X., Integrating Factor Method for Predicting the Developing Trend of Railway Track Irregularity, China Railway Science, 27(6), pp. 27-31, 2006.

[8] Xu, Y., Analysis of Development of Track Irregularities with Linear Forecast Model. Journal of Shijiazhuang Railway Institute, 18(1), pp. 6-9, 2005.

[9] Xu, P., Research on Characteristics of Track Dynamic Irregularity Variations on Railway Lines (Master dissertation). Beijing Jiaotong University, pp. 1-32, 2009.

[10] Ministry of railway of the People's Republic of China, Railway Line Maintenance Regulations, China Railway Publishing House, pp. 93-94, 2008.

[11] Ministry of Railway of the People's Republic of China, Explanatory Notes on Articles of Railway Line Maintenance Regulations, China Railway Publishing House, pp. 203-206, 2008. 